\title{
Mulheres Indígenas e suas coexistências - uma apresentação
}

\author{
NICOLE SOARES-PINTO \\ Universidade Federal do Espírito Santo, Vitória, Espírito Santo, Brasil \\ nicsoares@gmail.com \\ ANA MARIA RAMO Y AFFONSO \\ Universidade Federal de Santa Catarina, Florianópolis, Santa Catarina, Brasil \\ elfanark@hotmail.es \\ SANDRA BENITES \\ Universidade Federal do Rio de Janeiro, Rio de Janeiro, Rio de Janeiro, Brasil \\ sandraarabenites@gmail.com
}

DOI 10.11606/issn.2316-9133.v29i1p173-178

Ara Yma é, entre os Guarani, tempo de recolhimento. Diz-se que entre julho e setembro Nhanderu adentra os confins do universo e a Terra fica órfã de seu olhar. Eis que nesses tempos os parentes se agregam em torno do fogo de chão, compartilham os alimentos e ouvem os mais velhos contar histórias de tempos primevos, de ancestrais ainda presentes nas memórias e de suas próprias caminhadas pela Yvy Rupa. A história, aqui, é a atualização parcial e circunstancial de experiências de vida carregadas de ensinamentos. Ensinamentos de homens e de mulheres, mas são as mãos delas que ajeitam as lenhas e tições em torno dos quais as palavras nascem, giram e sobem aos ouvidos. Os artigos que compõe o presente dossiê foram em parte escritos sob o signo do recolhimento, do isolamento social e da espera em um tempo delicado de incertezas quanto ao porvir no contexto da pandemia de Covid19. São palavras escritas que surgem das conversas entre mulheres e das conversas das mulheres, entre o recolhimento e o encontro. Palavras de presentes, passados e futuros: daquilo que se faz a partir da força feminina da ancestralidade.

Trocar palavras é tecer histórias, pois a memória viva que passeia por entre os mundos indígenas é distribuída e é só coletivamente que adquirem seus sentidos. A memória narrada é a costura das coletividades e a possibilidade sempre atualizada de que a vida perdure. É de narrativas a costurar uma História Outra que trata este dossiê, que é resultado de um encontro que veio a acontecer na forma de um simpósio temático no $3^{\circ}$ Congresso Internacional Povos Indígenas da América Latina, entre os dias 03 a 05 de julho de 2019, na 
Universidade de Brasília. Sob o título "Mulheres indígenas e suas coexistências: inscrições etnográficas da relação entre gênero e terra”, o ST reuniu cerca de 20 trabalhos, divididos em três sessões temáticas: "Lideranças femininas e políticas do gênero", “Corpo e Território”, "Suportes e artefatos de gênero". As discussões, reflexões, enfrentamentos conceituais e descobertas coletivas durante o encontro não poderiam ser aqui restituídos sem que uma parte considerável quedasse perdida. No circuito de palavras que na ocasião estabelecemos, contudo, as mulheres não-indígenas se viram emaranhadas e deslumbradas pela mediação de uma sábia da grandeza de Sandra Benites, uma das organizadoras do Simpósio e deste dossiê; pela delicadeza conceitual de Sueli Maxacali; pela fortaleza da liderança política de Joziléia Kaingang; pela acuidade provocativa de Braulina Baniwa; pela experiência transformativa de mundos de Enoc Kichwa Canelos; pela energia jovial, combativa e cuidadosa de Soleane Manchineri. A cada trabalho discutido, uma nova constelação de ideias e mundos, e de formas femininas de figurá-los, se nos apresentavam.

Navegávamos guiadas por algumas perguntas: Como o feminino territorializa o mundo? Que mundos habitam os corpos femininos indígenas, e que corpos femininos habitam os mundos? Tínhamos como bússola a ambiguidade inerente a toda forma de ser, entre habitar e ser habitado, e sua relação com formas ou forças femininas. Mulheres pajés, mulheres-espíritos, rezadoras, mães-de-santo, guardadoras de segredos, pescadoras, parteiras, contadoras de histórias, agricultoras, literatas, musicistas, dançarinas, intelectuais, líderes políticas, cientistas, trabalhadoras, assalariadas, donas-de-casa, esportistas, fêmeas não-humanas, mães: o que de feminino brota na terra e pela terra? Como a criatividade feminina individualiza o mundo, criando espaços, lugares e deslocamentos? Como o feminino efetua e atualiza a relação entre humanos e não-humanos? De que forma propõe espaços de coexistência e resistência? $\mathrm{Na}$ chamada para os trabalhos dizíamos que nos interessavam etnografias cujas contribuições e intervenções pudessem se valer de vários formatos, sejam biografias ou autobiografias, artigos individuais ou em coautorias entre indígenas e não-indígenas, para além ou aquém da antropologia. E o que quer que pudermos lograr desse momento foi devido ao "encontro", que não visou produzir um consenso sobre os temas tratados ou mesmo propor uma agenda de pesquisa. Ao final, colhemos lampejos de ideias cuja principal característica é talvez sua capacidade de evidenciar as conexões e diferenças entre mundos sustentadas pelas mulheres indígenas. Algumas sementes, centelhas ou faíscas, somente, e a permanência da inquietude provocada pelas questões iniciais.

Todos os artigos aqui reunidos, seja no que está finalmente escrito, seja naquilo que os possibilita, dão notícias dos fios invisíveis de fortalecimento mútuo que ligam as mulheres indígenas entre si e ao mundo. Falam não só de si mesmas, mas da relação entre amizade e confiança. Falam de cuidar da vida, de si e dos outros. A fala escrita, essa trama de palavras, tempos e memórias, é a forma que toma aqui a resistência da vida indígena em suas territorializações femininas.

Mulheres indígenas (re)tomam a palavra: elas trazem até os espaços da academia as histórias de suas mães, tias e avós, costurando a memória viva e a palavra escrita. 
Escrevivência, conceito associado à premiada literata negra Conceição Evaristo e aqui convocado pela antropóloga Fran Baniwa. Escrever a experiência e viver a escrita, eis que é com esta palavra "Minha escrevivência, experiências vividas e diálogo com as mulheres indígenas do Rio Negro - Amazonas/Brasil", que Fran nos oferece a sua história. Situada em um "entre-mundos", ela decide falar da potência política de afirmar e reconhecer que as mulheres têm as suas próprias teorias para "explicar sua experiência no mundo e suas transformações". Autodeterminar-se, nos explica Fran, é se chamar pelo próprio nome ao aparecer frente ao outro, atentando aos nomes pelos quais outros querem ser chamados, em meio a "discursos de passagem e recebimento" como faziam os avós antigos sentados em seus banquinhos, "símbolos do banco da vida", na entrada da "Porta do Sol Nascente". As mulheres rionegrinas, essas "diplomatas étnicas", transportam consigo as suas linguagens, as suas formas de nomear, tecendo profundas redes cuja substância é a própria diferença. A terra, que é mãe para os Baniwa, repousa nesse diálogo em permanente atualização: eis a vida percorrendo, incansavelmente, memórias. A terra-mulher é esse espaço, esse entre-mundos do qual Fran desenha sua escrevivência, suas sempre renovadas possibilidades, e que nos oferta generosamente em seu artigo.

Contar novamente, contar outras histórias a partir de histórias. Confidências e histórias de amor mediadas por palavras ora cortantes ora macias sustentam a preciosa etnografia biográfica de Enoc Santi sobre seu amigo warmipangui - termo que designa as pessoas Kichwa Canelos que sentem atração sexual por outra de mesmo sexo. No artigo "La golondrina: Etnografía y concepciones de género, sexo y goce de un indígena Kichwa Canelos" conhecemos Shawa, seus desejos, afeições e cuidados com os outros, suas estratégias de persistência. Sustentada por uma relação de extrema confiança, a etnografia de Enoc colore alguns dos embotados conceitos de afeto que algumas vezes a discussão sobre gênero na etnologia ameríndia fez ressoar. Colorido que não se deixa esmaecer pela brutalidade da colonização e da evangelização, e a ela reage criticamente com a troca de afetos, carinhos e desfrute. Entre mortos, regalos, pilhérias, deuses cristãos e gozo, somos conduzidas a uma complexa rede de amor e resistência que anima essa grandiosidade chamada Shawa.

Por meio do encontro com documentos históricos da $2^{\circ}$ Inspetoria Regional do Pará do Serviço de Proteção aos Índios, de um lado, e da cosmologia tembé, de outro, o artigo de Ana Victória da Costa e Vanderlúcia Ponte busca entender as dinâmicas, as insurgências e resistências que se produziram acerca da saúde, da doença entre "corpos em contato" na região do Gurupi (fronteira entre o Pará e Maranhão). Seu artigo "Corpos em contato: subalternização, resistências e os Serviço de Proteção aos Índios na $2^{\circ}$ Inspetoria do Pará” contrapõe a violência histórica de Estado contra os povos indígenas aos procedimentos de cuidado, fortalecimento e metamorfose dos corpos femininos tembé. Somos agraciadas não só com uma atenta e precisa leitura sobre documentos históricos e as atrocidades ali constantes, como também com uma discussão importante acerca de saúde e doença desde a perspectiva do evento de contato. Talvez seja justamente de (re)leituras como essas que 
precisaremos cada vez mais. Revisitar o passado, palmilhar as situações de epidemia que acometeram os povos indígenas e, a partir de sua capacidade de resistência sustentada pela construção de corpos em coexistência com seres outros que humanos, imaginar outros futuros.

Relatos de experiências são o curso do rio que atravessa este Dossiê, fazendo emergir uma tríade que chama a atenção do leitor: experiência-narrativa-memória. Tudo indica que estamos frente a uma perspectiva ao mesmo tempo situada e aberta ao evento, alimentada pela fina percepção da concatenação dos tempos idos graças às continuidades que se adivinham no presente e, todas elas singulares, cada uma diferente. É assim que Melissa Oliveira, em seu artigo "Crônica sobre vida e morte: o que/como eu aprendi (d)aquilo que minhas amigas Tukano me mostraram do seu mundo" faz aparecer a experiência antropológica e os afetos pedagógicos provindos de suas amigas indígenas. Caminhando pelas comunidades, graças ao compartilhamento de alegrias, angústias e demais intimidades, as mulheres indígenas do Rio Negro se mostram por meio de uma imensa e profunda cotidianidade, a perpassar os grandes temas da etnologia: parentesco, mitos, rituais, xamanismo.

Por seu turno, ao manter o canto que revigora a memória, essa troca de palavras entre humanos e não-humanos, os Maxacali sustentam a trama da vida em uma paisagem que já virou outra. As mulheres maxacali com suas panelas de barro, água de batata e linha de embaúba, amansam as potências predatórias, dotando a socialidade dos remansos e calmarias tão necessários para a manutenção das alianças e afetos que constituem os territórios. Para além de oposições, os entrelaçamentos de fazeres e competências masculinos e femininos fluem constituindo "corpos-território" nesta "sociedade de xamãs". Assim como as mãos das mulheres Maxacali transformam substâncias perigosas, o artigo "Panela de barro, água de batata, linha de embaúba: práticas xamânicas das mulheres tikmũ ũnmaxakali" de Claudia Magnani, Ana Maria Gomes, Sueli Maxacali e Maisa Maxacali, essa escrita a oito mãos, possibilita uma renovação teórica graças à sua instigante proposta de requalificar as relações de gênero em termos de distintividade: "há que se pensar", nos dizem, "em polos divergentes e auto-implicantes que, todavia, jamais alcançam uma estabilidade, ou uma qualquer simetria".

Ailton Krenak apresenta a escrita de Eliane Potiguara como "Uma terra que grita". No poema "O Criador, a identidade e o guerreiro", a escritora pergunta: "Que me matas ou me faz viver/Que me faz sofrer ou me faz calar?” (POTIGUARA, 2018, p.67). Seria possível pensar a antropologia como "troca de palavras" enraizadas nessas perguntas? Acreditamos que a variação semântica da palavra "troca" nos ofereça instigantes questões. Será a antropologia um mecanismo de transformar as palavras e os mundos ao permitir aos conceitos diferir a partir do encontro com conceitos outros? Ao "trocar palavras" com as mulheres indígenas, somos convidadas a alterar os lugares da fala e a cultivarmos um local de escuta, e nos darmos um respiro para ouvir histórias, no recolhimento de um silêncio ativo que precisamos os não indígenas aprender a desfrutar. 
Os mundos das mulheres indígenas, como mostra o dossiê, pedem a palavra, muitas vezes a palavra que rasga a teoria e o conceitos ao meio, e a eles se mostram indomesticáveis. Este è um ato de uma intensidade política tão atual quanto necessário, porque pleno de possibilidades nestes tempos em que aparatos midiáticos devoradores de subjetividades e sonhos estão tão mais presentes quanto mais perdem a sua capacidade de fabulação e especulação criativa. Por outro lado, tais aparatos já não mais capazes de eclipsar o vínculo histórico entre a espoliação da Terra e a invisibilização das mulheres, entre o grito de Gaia, e o silenciamento de corpos femininos. Vínculos e gritos que já não se pode mais abafar. Silenciamento cujo degredo vem em socorro do futuro, para que ele exista.

Alguns dos artigos que ora podemos ler foram finalizados em meio ao temor, luto e tristeza pela perda de parentes ou anfitriões indígenas na pandemia da Covid-19. O tempo é curto: é preciso contar as histórias que atualizam a memória em defesa da vida. Somos agraciados com a eloquência dessas mulheres que, frente ao inusitado, ao inominável e às tantas violações que seus povos vêm sofrendo, tomam a palavra e, com muita coragem, nos contam de seus mundos e nos recontam os mundos próprios de Outros, entre eles os mundos não indígenas. Eis que na palavra há resistência. Narrar o presente, para abrir novos caminhos aos que virão. Já não temos mais o que acrescentar, convidamos a vocês a ouvirem esses outros modos de viver, falar e trocar.

\section{Referências Bibliográficas}

POTIGUARA, Eliane. (2018). Metade Cara, Metade Máscara. 3a Edição. Rio de Janeiro:

Grumin.

\section{sobre as autoras}

\section{Nicole Soares-Pinto}

É professora do Departamento e do Programa de PósGraduação em Ciências Sociais da Universidade Federal do Espírito Santo, com doutorado em Antropologia pela Universidade de Brasília e mestrado em Antropologia Social pela Universidade Federal do Paraná. Realiza atualmente estágio pós-doutoral no Museu Nacional-UFRJ.

\section{Ana María Ramo-Affonso}

Atua como professora substituta na Universidade Federal de Santa Catarina, onde também realizou estágio pós-doutoral. Tem título de doutora em Antropologia pela Universidade Federal Fluminense, e em História y Geografia pela Universidad Complutense de Madrid. Também é mestra em Antropologia pela Universidade Federal de Minas Gerais. 


\section{Sandra Benítes Guarani Nhandewa}

Mestre em antropologia social pelo Museu Nacional -UFRJ e doutoranda na mesma instituição. Curadora-adjunta no Museu de Arte de São Paulo (MASP)

Recebido em 09/08/2019

Aceito para publicação em 19/06/2020 